\title{
Pertumbuhan rumput laut Kappaphycus alvarezii yang dibudidayakan bersama Eucheuma denticulatum dengan komposisi berbeda
}

\section{(The growth of seaweed Kappaphycus alvarezii cultivated with Eucheuma denticulatum with different composition)}

\author{
Meichel Pandensolang, Indra Salindeho, Joppy Mudeng
}

\begin{abstract}
The objective of this study was to determine the growth of seaweed Kappaphycus alvarezii cultivated with Eucheuma denticulatum with different composition. This research was carried out for six weeks, from March to April 2013, in the coastal waters of Sondaken village, Tatapaan District, South Minahasa regency, North Sulawesi. The experiment was designed according to completely randomized design with four treatments and three replications. The four tested treatments were the different composistion of tied seaweed in a long-line raft, where treatment A: $100 \% \mathrm{~K}$. alvarezii, ; B: 50\% K. alvarezii and 50\% E. denticulatum, on each culture line, two types of algae were tied in sequence; C: $75 \% \mathrm{~K}$. alvarezii and $25 \% \mathrm{E}$. denticulatum, in which in each line, every three bunch of $K$. alvarezii was followed by one bunch of E. denticulatum; D: $25 \%$ of $K$. alvarezii and $75 \% E$. denticulatum, on each culture line, every three bunch of $E$. denticulatum was followed by one bunch of $K$. alvarezii. Each experimental unit was a $3 \mathrm{~m} \times 3,4 \mathrm{~m}$ rectangular line raft containing four culture lines where the bunch of the tested seaweed were tied. Data collection was performed every two weeks by weighing the tested $K$ alvarezii. The data were statistically analyzed (ANOVA) using JMP statistical program (SAS-institute). The results showed that absolut growth, relative growth and daily growth rate of $K$. alvarezii was not significantly affected by the tested treatments (Prob> F $>0.5$ ). Thus, the occurence of $E$. denticulatum in whatever abundance in K. alvarezii cultivation area will not affect the growth of K. alvarezii.
\end{abstract}

Keywords: Seaweed, K. alvarezii, E. denticulatum, growth

\section{PENDAHULUAN}

Sulawesi Utara menyimpan potensi pengembangan budidaya rumput laut yang besar karena berada di daerah tropis, letak geografisnya yang berbatasan dengan laut pasifik yang kaya akan sumberdaya hayati laut (Sirait, 2007). Keppel (2002) mengemukakan bahwa rumput laut penghasil karagenan khususnya dari genus Eucheuma telah dibudidayakan di beberapa lokasi seperti di Pulau Nain,
Likupang, Wori, Tumpaan, Lembean Timur, Belang Bitung dan Sangihe.

Saat ini sebagian masyarakat pembudidaya rumput laut di Sulawesi Utara juga membudidayakan $E$. denticulatum sebagai alternatif untuk menggantikan Kappaphycus alvarezii yang sering gagal panen akibat serangan penyakit ice-ice. Berdasarkan informasi dari masyarakat pembudidaya di Desa Arakan, Minahasa Selatan, yang pernah 
mencoba membudidayakan kedua rumput laut ini secara bersama, jika K. alvarezii dan E. denticulatum dipelihara secara bersamaan pada wadah yang sama, pertumbuhan $K$. alvarezii akan terhambat dan E. denticulatum yang akan bertumbuh dengan cepat.

Berdasarkan informasi dan beberapa alasan tersebut di atas maka penelitian ini dilaksanakan untuk menguji secara ilmiah tentang pertumbuhan rumput laut $K$. alvarezii yang dibudidayakan bersama dengan E. denticulatum.

\section{BAHAN DAN METODE}

Penelitian ini dilaksanakan di perairan pantai Desa Sondaken, Kecamatan Tatapaan, Kabupaten Minahasa Selatan, Propinsi Sulawesi Utara, mulai bulan Maret sampai April 2013.

Percobaan ini dirancang menurut Rancangan Acak Lengkap (RAL) dengan 4 perlakuan dan 3 ulangan sehingga secara keseluruhan terdapat 12 satuan percobaan. Faktor yang akan diuji melalui perlakuan dalam percobaan ini adalah perbedaan komposisi rumput laut Kappaphycus alvarezii dan Eucheuma denticulatum yang dipelihara bersama dalam satu wadah. 4 komposisi berbeda yang menjadi perlakuan adalah:

- Perlakuan A : $100 \%$ K. alvarezii,.

- Perlakuan B : 50\% K. Alvarezii dan $50 \%$ E. denticulatum.

- Perlakuan C : 75\% K. Alvarezii dan 25\% E. denticulatum.

- Perlakuan D : 25\% K. alvarezii dan 75\% E.denticulatum

Untuk perlakuan A, pada setiap tali ris diikat satu jenis rumput laut uji yakni $K$. Alvarezii. Pada perlakuan B, untuk setiap tali ris diikat dua jenis rumput laut uji, yang diikat secara bergantian. Setiap 1 ikatan K. alvarezii diikuti oleh 1 ikatan E. denticulatum, dan demikian seterusnya. Pada perlakuan C, untuk setiap tali ris diikatkan 2 jenis rumput laut uji, dimana setiap 3 ikatan $K$. alvarezii diikuti oleh 1 ikatan E. denticulatum, dan demikian seterusnya. Pada perlakuan D, pada setiap tali ris diikatkan 2 jenis rumput laut uji, dimana setiap 1 ikatan $K$. alvarezii, diikuti oleh 3 ikatan E. denticulatum, dan demikian seterusnya. Dalam 1 wadah percobaan terdapat 64 rumpun rumput laut uji.

Wadah untuk setiap satuan percobaan didesain membentuk persegi panjang dengan ukuran $3,4 \times 3 \mathrm{~m}^{2}$, dan dalam setiap wadah terdapat 4 ujung tali ris masing-masing dengan panjang 3,8m. Jarak antara tali ris yaitu $75 \mathrm{~cm}$, dan pada setiap tali ris diikatkan 16 rumpun rumput laut dengan jarak antar rumpun adalah 20 $\mathrm{cm}$.

\section{Analisis data}

Data hasil pengukuran pertambahan berat selama 6 minggu dikonversi menjadi pertumbuhan mutlak, pertumbuhan relatif dan laju pertumbuhan harian dengan menggunakan formula di bawah ini :

\section{a) Pertumbuhan mutlak}

Mengikuti formula yang ada pada (Efendie, 1979 dalam Wattimury, 2008) :

$$
\begin{aligned}
\Delta \mathbf{W}= & \mathbf{W t}-\mathbf{W o} \\
\text { dimana, } \Delta \mathrm{W}= & \text { Pertumbuhan mutlak } \\
& \text { dalam berat (gram) } \\
\mathrm{Wt} \quad & \text { Berat rata-rata rumput } \\
& \text { laut uji pada akhir } \\
& \text { percobaan (gram) }
\end{aligned}
$$




$$
\begin{aligned}
\text { Wo }= & \text { Berat rata-rata rumput laut } \\
& \text { uji pada awal percobaan } \\
& \text { (gram) }
\end{aligned}
$$

\section{b) Pertumbuhan relatif}

Pertumbuhan relatif (Weatherley and Gill, 1989,) dalam (Wattimury, 2008) :

$$
\operatorname{Gr}(\%)=\frac{W t-W o}{W o} \times 100
$$

dimana :

$$
\begin{aligned}
\operatorname{Gr}(\%)= & \text { Pertumbuhan relatif (\%) } \\
\text { Wt } & =\text { Berat akir percobaan } \\
& \text { (gram) } \\
\text { Wo } & =\text { Berat awal percobaan } \\
& \text { (gram) }
\end{aligned}
$$

\section{c) Pertumbuhan harian}

Laju pertumbuhan harian didapatkan dengan menggunakan rumus sebagai berikut, Penniman et al. (1986) dalam Wattimury, (2007).

$$
\mathrm{G}=\left\{\left[\frac{\mathrm{Wt}}{\mathrm{Wo}}\right]^{\frac{1}{\mathrm{t}}}-1\right\} \times 100 \%
$$

$$
\begin{aligned}
\text { Dimana }: \mathrm{G}= & \text { Laju pertumbuhan perhari } \\
\mathrm{Wt}= & \text { Berat pada saat } \\
& \begin{array}{l}
\text { pengukuran } \\
\text { (gram) }
\end{array} \\
\text { Wo }= & \text { Berat pada saat penebaran } \\
& \text { (gram) } \\
\mathrm{t}= & \text { Waktu penelitian (hari) }
\end{aligned}
$$

\section{HASIL DAN PEMBAHASAN}

\section{a. Pertumbuhan mutlak}

Gambar 1 menunjukan bahwa rumput laut $K$. alvarezii dan $75 \%$ E. denticulatum pada perlakuan $\mathrm{D}$ memiliki pertumbuhan mutlak tertinggi (175,92 gr). Selanjutnya diikuti oleh perlakuan C (75\%
K. alvarezii dan 25\% E. denticulatum) dengan pertumbuhan mutlak 172,3 gr, kemudian perlakuan B $(50 \%$ K. alvarezii dan $50 \%$ E. denticulatum) pertumbuhan mutlak 170,17 gr. Perlakuan A (100\% K. alvarezii) memiliki pertyumbuhan mutlak terendah (165.16 gr).

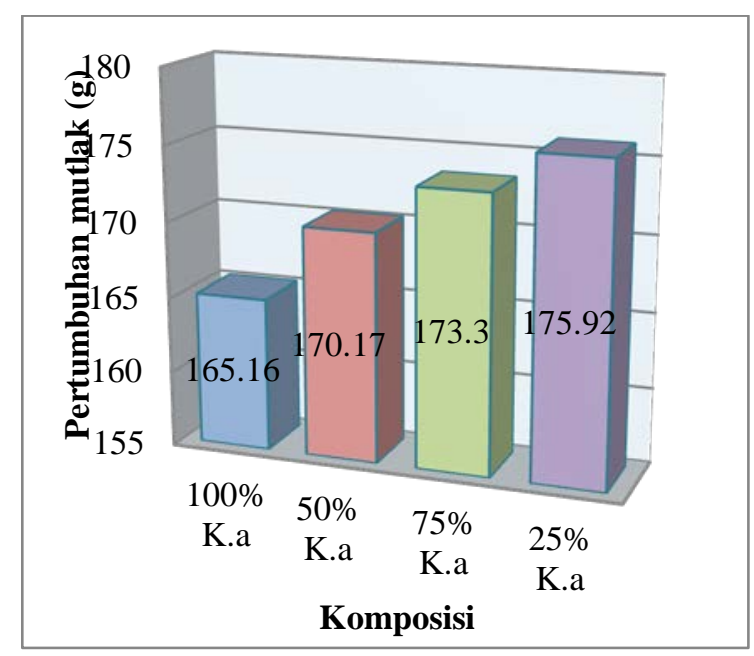

Gambar 1. Pertumbuhan mutlak $K$. alvarezii yang dibudidayakan secara bersama dengan $E$. denticulatum dengan komposisi berbeda

Akan tetapi hasil sidik ragam menunjukan bahwa pertumbuhan mutlak rumput laut tidak secara nyata dipengaruhi oleh perbedaan perlakuan atau dengan kata lain perbedaan komposisi rumput laut $K$. alvarezii dan E. denticulatum pada wada budidaya yang sama tidak memberikan pengaruh nyata terhadap pertumbuhan rumput laut $K$. alvarezii. (nilai "Prob > F, $0,3420>$ F 0,05)

\section{b. Pertumbuhan relatif}

Gambar 2 menunjukan bahwa rumput laut $K$. alvarezii yang diberi perlakuan D (25\% K. alvarezii) memiliki pertumbuhan relatif tertinggi (178,14\%), diikuti rumput laut yang diberi perlakuan $\mathrm{C}$ (75\% K. alvarezii dan 25\% E. denticulatum) dengan pertumbuhan relatif sebesar 170,3 gram. Kemudian rumput laut 
yang diberi perlakuan B (50\% K. alvarezii dan $50 \%$ E. denticulatum) dengan pertumbuhan relatif sebesar 167,24 gram dan pertumbuhan relatif terkecil ditunjukan oleh rumput laut yang diberi perlakuan A ( $100 \%$ K. alvarezii) yaitu, 162,82 gram.

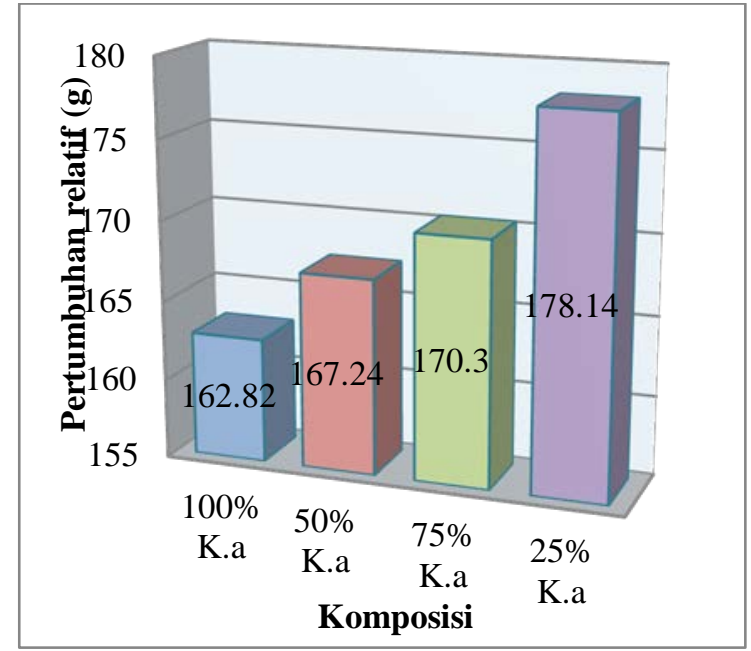

Gambar 2. Pertumbuhan Relatif (\%) $K$. alvarezii yang dibudidayakan secara bersama dengan $E$. denticulatum dengan komposisi berbeda

Akan tetapi hasil analisis keragaman menunjukan bahwa perbedaan perlakuan yakni perbedaan komposisi $K$. alvarezii dan E. denticulatum yang dipelihara pada satu wadah budidaya tidak memberikan pengaruh yang nyata terhadap perbedaan pertumbuhan rumput laut $K$. alvarezii (nilai "Prob > F", 0,1417 > 0,05).

\section{c. Laju pertumbuhan harian}

Gambar 3 menunjukan bahwa rumput laut yang dibudidayakan dengan perlakuan D dengan komposisi 25\% $K$. alvarezii dan E. denticulatum 75\% memperoleh persentase laju pertumbuhan harian tertinggi (2,46\%), diikuti oleh perlakuan C komposisi 75\% K. alvarezii dan $25 \%$ E. denticulatum dengan laju pertumbuhan harian 2,39\%. Kemudian perlakuan B (50\% K. alvarezii dan 50\% E. denticulatum) yang dengan laju pertumbuhan harian 2,36\% dan laju pertumbuhan harian terkecil pada perlakuan A dengan komposisi $100 \% \mathrm{~K}$. alvarezii yang hanya sebesar 2,32\%.

Akan tetapi hasil sidik ragam menunjukan bahwa perbedaan pertumbuhan harian rumput laut tidak dipengaruhi secara nyata oleh perbedaan perlakuan atau dengan kata lain perbedaan komposisi rumput laut $K$. alvarezii dan $E$. denticulatum pada satu wadah budidaya tidak memberikan pengaruh yang nyata terhadap perbedaan pertumbuhan harian rumput laut $K$. alvarezii (nilai “ Prob > F “, $0,0677>0,05)$.

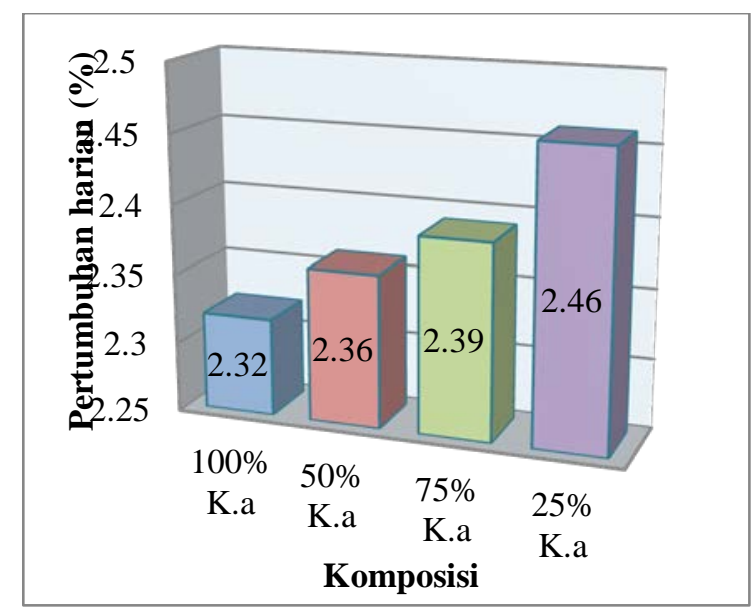

Gambar 3. Pertumbuhan harian (\%) $K$. alvarezii yang dibudidayakan secara bersama dengan $E$. denticulatum dengan komposisi berbeda

Dari hasil pengamatan terhadap pertumbuhan rumput laut uji pada masingmasing perlakuan, keberadaan $E$. denticulatum yang dibubudidayakan dengan K. alvarezii dalam satu wadah kultur yang sama justru menyebabkan pertumbuhan K.alvarezii sedikit lebih baik walaupun tidak nyata secara statistik. Hal ini dapat dilihat dari perbandingan pertumbuhan $K$. alvarezii pada perlakuan A dengan komposisi ikat $100 \% \quad K$. alvarezii dengan pertumbuhan harian 
terkecil, yaitu 2,27\% dan K. alvarezii pada perlakuan D (25\% K. alvarezii dan 75\% E. denticulatum) yang memiliki pertumbuhan harian tertinggi yaitu 2,46\%. Jika memang benar-benar alga $E$. denticulatum dapat menghambat pertumbuhan, maka laju pertumbuhan alga uji $K$. alvarezii pada perlakuan D akan memberikan hasil pertumbuhan yang kecil dan K. alvarezii pada perlakuan A akan lebih tinggi karena dikultur tanpa ada E. denticulatum.

Penelitian terhadap pertumbuhan rumput laut $K$. alvarezii dan $E$. denticulatum juga dilakuan oleh Msuya dan Salum (2007). Perlakuan yang dicobakan yaitu, kedua rumput laut ini dipelihara bersama lamun dan tanpa lamun. Hasil penelitiannya menunjukan bahwa keberadaan lamun yang dipelihara bersama dapat mempengaruhi menghambat pertumbuhan alga $E$. denticulatum, tetapi tidak pada pertumbuhan K. alvarezii. Sama halnya dengan lamun, E. denticulatum juga merupakan tumbuhan air yang juga memerlukan nutrien dan sebagainya untuk mendukung pertumbuhannya dan dapat bersifat kompetitor bagi spesies alga lainnya seperti $K$. alvarezii. Akan tetapi, hasil penelitian ini menunjukan bahwa keberadaan E. denticulatum tidak dapat menekan pertumbuhan rumput laut $K$. alvarezii.

Mudeng (2007) melakukan penelitian terhadap pertumbuhan $K$. alvarezii dan E. denticulatum. Hasil penelitiannya memperoleh pertumbuhan harian K. alvarezii 3,53 - 3.72 \% dan $E$. denticulatum 3,91 - 4,56 \%. Selanjutnya Wikibia et al (2002) melakukan penelitian terhadap pertumbuhan kedua spesis ini dan hasil penelitianya menunjukan bahwa prosentase pertumbuhan alga $E$. denticulatum strain coklat memiliki tingkat pertumbuhan yaitu 4,7 \% dan K. Alvarezii dengan pertumbuhan 4,3 \%. Data-data ini menunjukan bahwa pertumbuhan kedua spesies rumput laut ini tidak terlalu jauh berbeda meskipun pertumbuhan alga $E$. denticulatum cenderung sedikit lebih tinggi dibandingkan dengan K. alvarezii.

Studi mengenai pertumbuhan rumput laut khususnya $K$. alvarezii telah banyak dilakukan oleh beberapa peneliti. Taridisan (2007) melalui penelitianya dengan perlakuan berat awal dan jarak ikat berbeda memperoleh laju pertumbuhan harian rumput laut $K$. alvarezii 4,55\% yang diperoleh dari perlakuan berat 150 gram dan jarak ikat $40 \mathrm{~cm}$. Soenardjo (2004) melakukan penelitian untuk mengetahui pertumbuhan alga $K$. alvarezii dan memperoleh laju pertumbuhan harian 4,4\%. Anggadiredja dkk (2006) megemukakan bahwa laju pertumbuhan harian yang baik untuk rumput laut Eucheuma sp adalah tidak kurang dari 3\%.

Jika data-data tersebut di atas dibandingkan dengan hasil penelitian di Desa Sondaken yang memperoleh laju pertumbuhan harian alga $K$. alvarezii dengan kisaran 2,32 - 2,46 \%, maka dapat dikatakan bahwa, pertumbuhan rumput laut di Desa Sondaken tidak memenuhi standar minimal pertumbuhan harian 3\%. Berdasarkan pengamatan selama masa penelitian, sangat jarang ada masyarakat yang membudidayakan rumput laut, menurut keterangan dari beberapapa pembudidaya di Desa Sondaken kondisi cuaca dan lingkungan pada saat ini menjadi alasan mengapa mereka tidak membudidayakan rumput laut. Arisandi, dkk (2011) mengemukakan bahwa pertumbuhan rumput laut lambat akibat 
kondisi lingkungan yang tidak mendukung pada bulan-bulan tertentu, merupakan masalah yang sering dihadapi oleh pembudidaya rumput laut. Umumnya pada kondisi tersebut rumput laut mengalami kekerdilan dan terserang hama atau penyakit.

\section{KESIMPULAN}

Pertumbuhan rumput laut $K$. alvarezii tidak nyata dipengaruhi oleh perbedaan komposisi. Dengan demikian dapat dikatakan bahwa rumput laut $E$. denticulatum tidak mempengaruhi pertumbuhan $K$. alvarezii, maka kedua jenis rumput laut ini bisa dipelihara bersama-sama walaupun dalam wadah kultur yang sama.

\section{UCAPAN TERIMA KASIH}

Disampaikan ucapan terima kasih kepada saudara Sony Sasongke, S.Pi. yang sudah memfasilitasi dalam persiapan lokasi penelitian dan penyediaan benih rumputlaut uji.

\section{DAFTAR PUSTAKA}

Anggadiredja JT, Achmad Z, Purwoto H, Istini S, 2006. Rumput Laut. Penebar Swadaya. Jakarta. 147 hal. Arisandi A, Marsoedi, Nursyam H

Sartimbul A, 2011. Kecepatan dan

Presentase Penyakit ice-ice Pada

Kappaphycus alvarezii di Perairan

Bluto Sumenep. Junrnal Ilmiah

Perikanan dan Kelautan. 3 (1)

Keppel RC. 2002. Prospek Penbembangan

Sumberdaya Rumput Laut di

Sulawesi Utara.JurnalUniversitas

Sam Ratulangi (4) : 38 - 42

Mudeng, J. D, 2007. Pertumbuhan Rumput
Laut Kappaphycus alvarezii dan

Eucheuma denticulatum Pada

Kedalaman Berbeda di Perairan

Pulau Nain Sulawesi Utara.Tesis.

Program Pasca Sarjana Universitas

Sam Ratulangi. 61 ha

Msuya and Salum, 2012. Effect of the

Presence of Seagrass and Nutrients

on Growht Rates of Farmed

Kappaphycus alvarezii and

Eucheuma denticulatum

(Rhodophyta). Western Indian

Ocean J. Mar. Sci. 10 (2) : 129-135

Sirait DY. R, 2007. Pertumbuhan Alga

Laut Eucheuma denticulatum dan

Keberadaan Organisme Epifit Pada

Kedalaman Berbeda Di Perairan

Pulau Nain, Kecamatan Wori,

Kabupaten Minahasa Utara

Sulawesi Utara. Skripsi Fakultas

Perikanan dan Ilmu Kelautan.

Universitas Sam Ratulangi.

Manado

Soenardjo N., 2004. Aplikasi Budidaya

Rumput Laut Eucheuma cottonii

(Weber van Bosse) Dengan Metode

Jaring Lepas Dasar (Net Bag)

Model Cidaun. Buletin Oseanografi

Marina. Oktober 2011.(1): 36 - 44

Taridisan, S.R., 2007. Pertumbuhan

Rumput Laut (Eucheuma cottonii)

Yang Dibudidayakan Dengan Jarak

Ikat dan Berat Awal Yang Berbeda

Di Perairan Salibabu Kecamatan

Lirung Selatan Kabupaten

Kepulauan Talaud. Skripsi Fakultas

Perikanan dan Ilmu Kelautan.

Universitas Sam Ratulangi.

Manado. 58 hal

Wattimury K., 2008. Pertumbuhan Rumput

Laut Eucheuma denticulatum Yang

Dibudidayakan Pada Kedalaman

Dan Berat Awal Berbeda Di

Perairan Pulau Nain, Kabupaten

Minahasa Utara. Skripsi Fakultas

Perikanan dan Ilmu Kelautan.

Universitas Sam Ratulangi.

Manado. 39 hal 
Wikibia J. G., Bolton J. J., Keats D. W., and Raitt L. M, 2002. Factors influencing the growth rates of three commercial eucheumoids at coastal sites in southern Kenya. Eighteenth International Seaweed Symposium Developments in Applied Phycology Volume 1, 2007, pp 339-347. Website : http://link.springer.com/chapter/10. 1007\%2F978-1-4020-5670-3_41 